\title{
Experimental transmission of Anaplasma marginale by male Dermacentor reticulatus
}

\author{
Zorica Zivkovic*1, Ard M Nijhof ${ }^{1}$, José de la Fuente ${ }^{2,3}$, Katherine M Kocan ${ }^{3}$ \\ and Frans Jongejan ${ }^{1,4}$
}

\begin{abstract}
Address: ${ }^{1}$ Utrecht Centre for Tick-borne Diseases (UCTD), Department of Infectious Diseases and Immunology, Faculty of Veterinary Medicine, Utrecht University, Yalelaan 1, 3584CL, Utrecht, The Netherlands, 2Instituto de Investigación en Recursos Cinegéticos IREC (CSIC-UCLM-JCCM), Ronda de Toledo s/n, 13071 Ciudad Real, Spain, ${ }^{3}$ Department of Veterinary Pathobiology, Center for Veterinary Health Sciences, Oklahoma State University, Stillwater, OK 74078, USA and ${ }^{4}$ Department of Veterinary Tropical Diseases, Faculty of Veterinary Science, University of Pretoria, Private Bag X04, 0110, Onderstepoort, South Africa
\end{abstract}

Email: Zorica Zivkovic* - Z.Zivkovic@vet.uu.nl; Ard M Nijhof - a.m.nijhof@vet.uu.nl; José de la Fuente - jose_delafuente@yahoo.com; Katherine M Kocan - Katherine.Kocan@okstate.edu; Frans Jongejan - f.jongejan@vet.uu.nl

* Corresponding author

Published: 30 November 2007

BMC Veterinary Research 2007, 3:32 doi:10.1/86/1746-6/48-3-32

This article is available from: http://www.biomedcentral.com/I746-6/48/3/32

(c) 2007 Zivkovic et al; licensee BioMed Central Ltd.

This is an Open Access article distributed under the terms of the Creative Commons Attribution License (http://creativecommons.org/licenses/by/2.0), which permits unrestricted use, distribution, and reproduction in any medium, provided the original work is properly cited.
Received: 14 September 2007

Accepted: 30 November 2007

\begin{abstract}
Background: Bovine anaplasmosis has been reported in several European countries, but the vector competency of tick species for Anaplasma marginale from these localities has not been determined. Because of the wide distributional range of Dermacentor reticulatus within Europe and the major role of Dermacentor spp. as a vector of A. marginale in the United States, we tested the vector competency of $D$. reticulatus for $A$. marginale.

Results: Male $D$. reticulatus were allowed to feed for 7 days on a calf persistently infected with a Zaria isolate of $A$. marginale, after which they were removed and held off-host for 7 days. The ticks were then allowed to feed a second time for 7 days on a susceptible tick-naïve calf. Infection of calf No. 4291 was detected 20 days post exposure (p.i.) and confirmed by msp4 PCR. Thirty percent of the dissected acquisition fed ticks was infected. In addition, $A$. marginale colonies were detected by light microscopy in the salivary glands of the acquisition fed ticks. Transmission of $A$. marginale to calf No. 9191 was confirmed by examination of Giemsa-stained blood smears and msp4 PCR. Ticks were dissected after transmission feeding and presence of $A$. marginale was confirmed in $18.5 \%$ of the dissected ticks.

Conclusion: This study demonstrates that $D$. reticulatus males are competent vectors of $A$. marginale. Further studies are needed to confirm the vector competency of $D$. reticulatus for other A. marginale strains from geographic areas in Europe.
\end{abstract}

\section{Background}

Bovine anaplasmosis is one of the most important tickborne diseases of ruminants worldwide. The disease is caused by infection of cattle with the obligate intraerythrocytic bacteria Anaplasma marginale which is classified in the family Anaplasmataceae, order Rickettsiales [1]. The acute phase of the bovine anaplasmosis is characterized by anemia, icterus, weight loss, fever, abortion, decreased milk production and often results in death [2]. Animals surviving the acute phase develop a lifelong persistent 
infection and can serve as reservoirs for mechanical transmission and biological transmission by ticks [3].

Anaplasmosis is endemic in tropical and sub-tropical regions where the disease constitutes a constraint to the cattle production. In Europe anaplasmosis is endemic in several Mediterranean countries including Italy $[4,5]$, Portugal [6] and Spain [7], and has occasionally been reported in Austria [8], Switzerland [9] and Hungary [10]. Mechanical transmission of $A$. marginale is effected by blood-contaminated fomites, including hypodermic needles, castration instruments, ear tagging devices, tattooing instruments, and dehorning saws or by blood-contaminated mouthparts of biting flies [11]. Biological transmission is effected by ticks and over 20 species of ticks have been incriminated as vectors worldwide [12]. While the one-host ticks, Rhipicephalus (Boophilus) microplus and $R$. annulatus, were eradicated from the United States in the early 1940s, they are the main tick vectors in tropical and subtropical areas [13]. Currently, Dermacentor spp. (D. andersoni, D. variabilis and D. albipictus) are the major tick vectors of A. marginale in the U.S. [14].

A. marginale undergoes a complex developmental cycle in ticks that begins with infection of gut cells from infected erythrocytes ingested with the tick bloodmeal $[15,16]$. Development of the final infective stage occurs in salivary glands from where the pathogen is transmitted to cattle. A major means of $A$. marginale transmission appears to be by male Dermacentor ticks which become persistently infected. These males are intermittent feeders and can feed and transmit $A$. marginale multiple times as they transfer among cattle, thus effecting intrastadial transmission $[15,16]$.

The vectorial capacity of tick species for A. marginale in Europe has not been well defined. Recent reports of endemicity of anaplasmosis in European countries [10] and of outbreaks in countries previously thought to be free of anaplasmosis, including Switzerland, warranted studies on the role of putative tick vector(s) [17]. The broad distribution range of $D$. reticulatus, which extends from the British isles to Central Asia [18], as well as the expanded geographic distribution of this tick as recently reported in Germany [19], Hungary [20] and the Netherlands [21], warrants further study of $D$. reticulatus as a vector for $A$. marginale in Europe.

\section{Results}

\section{Infection and acquisition feeding}

Infection of calf No. 4291 with the A. marginale Zaria isolate was detected on day 20 post exposure (PI) when the body temperature increased to $39.9^{\circ} \mathrm{C}$ and depression and anorexia were observed. The percent reduction PCV was $50 \%$ and the A. marginale percent parasitized erythrocytes (PPE) was 6\% (Table 1). A. marginale infection was subsequently confirmed by msp4 PCR. After infestations of the calf on the day 34 p.i. with 80 male and 5 female $D$. reticulatus ticks when the PPE was $0.6 \%$ (minimum 1000 erythrocytes counted), all female ticks and 66 of the male ticks attached and fed successfully. Based on PCR testing of one salivary gland from each of the 30 male tick halves, the infection percentage was $30 \%$. The presence of $A$. marginale colonies in salivary gland cells was confirmed by light microscopy examination (Figure 1) in the other half of the PCR positive ticks.

\section{Transmission feeding}

Male D. reticulatus ticks transmitted A. marginale Zaria isolate to calf No. 9191 . On day 27 p.i. the calf tested PCR positive. Inclusion bodies were detected in erythrocytes on day 35 in Giemsa-stained blood smears and the peak parasitemia was $2 \%$. While minimal clinical symptoms of anaplasmosis were observed, the body temperature increased during the peak of parasitemia up to $39.9^{\circ} \mathrm{C}$, the percent reduction PCV was $37.5 \%$ (Table 1) and the mucosal membranes became pale. Five out of 27 (18.5\%) ticks that were attached successfully were PCR positive for A. marginale.

\section{Verification of isolate identity}

The A. marginale isolate genetic identity was confirmed by PCR in samples collected during persistent infection in calf, during replication and development in ticks and after subsequent transmission to the susceptible calf. Subsequent sequencing of the $m s p 4$ and $m s p 1 \alpha$ genes also confirmed the isolate identity since the $m s p 4$ and $m s p 1 \alpha$ sequences were the same in all tick and cattle samples. The msp1 $\alpha$ sequence of the Zaria isolate contained two novel

Table I: Clinical findings of acquisition and transmission feeding of $D$. reticulatus ticks.

\begin{tabular}{cccccc}
\hline Calf number & $\begin{array}{c}\text { Number of ticks/ } \\
\text { feeding (days) }\end{array}$ & $\begin{array}{c}\text { Incubation period } \\
\text { (days) }\end{array}$ & $\begin{array}{c}\text { Maximum } \\
\left.\text { temperature ( }{ }^{\circ} \mathbf{C}\right)\end{array}$ & $\begin{array}{c}\text { PCV reduction } \\
\text { (\%) }\end{array}$ & $\begin{array}{c}\text { Maximum } \\
\text { parasitemia (\%) }\end{array}$ \\
\hline $4291^{\mathrm{a}}$ & $80 / 7$ & 20 & 39.9 & 50 & 6 \\
$9191^{\mathrm{b}}$ & $30 / 7$ & 35 & 39.9 & 37.5 & 2 \\
\hline
\end{tabular}

a Infected intravenously with $A$. marginale (Zaria isolate) blood stabilate.

$\mathrm{b}$ Infested with $D$. reticulatus adult males fed on calf 4291 .

c Number of days to first observation of infected blood cells on a stained blood smears. 


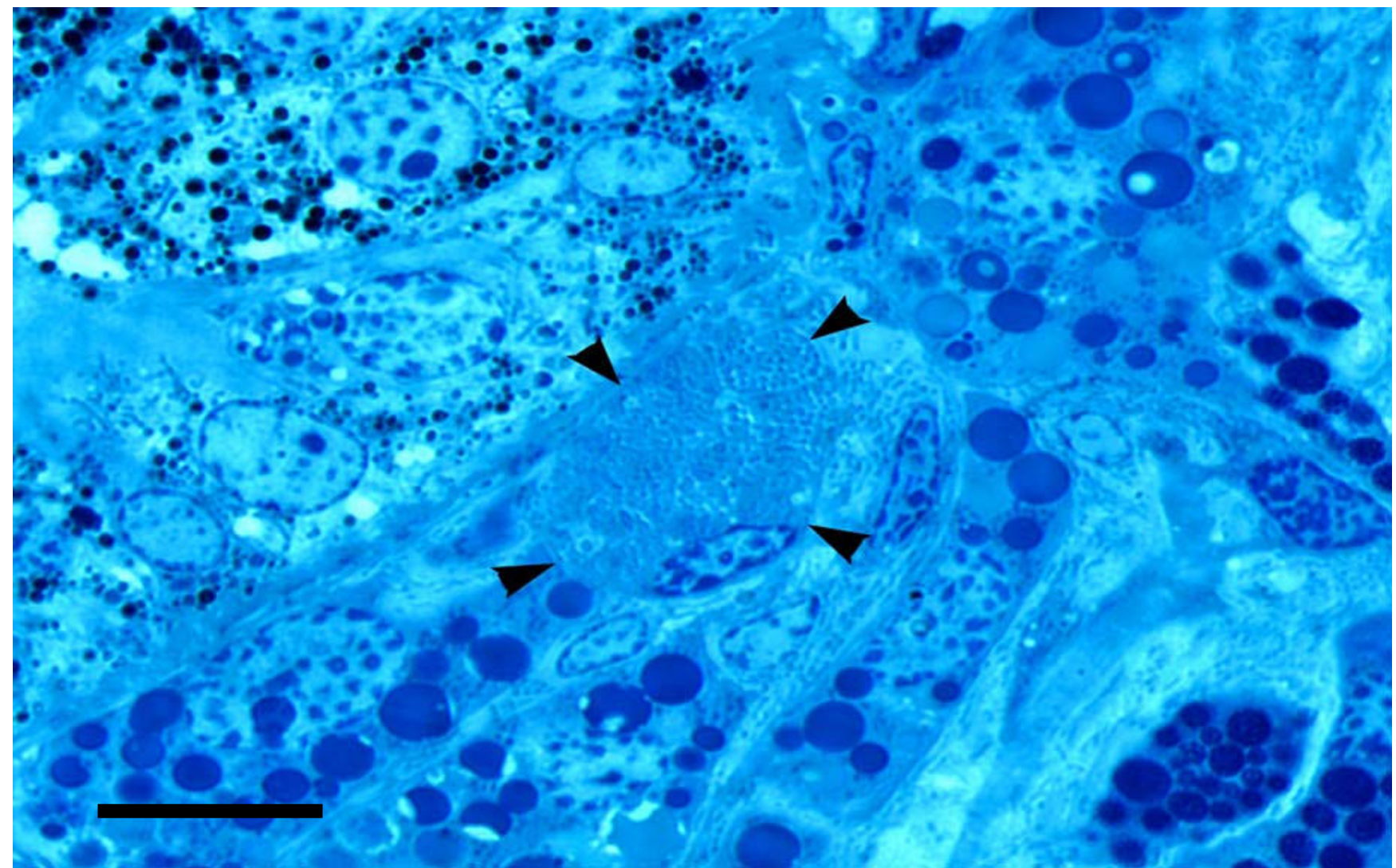

Figure I

Light micrograph of male $D$. reticulatus salivary gland cell containing several $A$. marginale colonies (arrowheads). Bar $=10 \mu \mathrm{m}$.

repeat forms which were labelled as 54 and 55 following the nomenclature of de la Fuente et al.[22] (Figure 2).

\section{Sequence accession numbers}

The GenBank accession numbers for msp $1 \alpha$ and $\operatorname{msp} 4$ sequences of the Zaria isolate of A. marginale are [GenBank: EU106083] and [GenBank: EU106082] respectively.

\section{Discussion}

A. marginale infection in cattle and wild ruminants was reported in several parts of Europe, including the Mediterranean countries of Spain and Portugal $[6,7]$, Italy $[4,5]$, and occasionally in France [23], the Alpine region of Switzerland [8,17] and more recently in Hungary [10]. However, the epidemiology of anaplasmosis in Europe has not been thoroughly investigated and local vector species were not identified.

In the Mediterranean region, several tick species have been incriminated as the potential biological vectors of $A$. marginale. Hyalomma m. marginatum and Rhipicephalus bursa were found on Iberian red deer in Spain that proved to be infected with A. marginale [7] and these ticks were therefore listed as putative tick vectors. Furthermore, $A$. marginale is endemic in Sicily and has been reported elsewhere from Italy, and several tick species have been identified in this area that may be vectors, including Rhipicephalus turanicus and Haemaphysalis punctata that were collected from A. marginale infected cattle [5].

Although anaplasmosis was reported in more northern latitudes, the tick vectors have not been identified. For instance, $A$. marginale was recently reported to be endemic in Hungary and the predominant tick species present on cattle in the study area was D. reticulatus [10]. In the United States, several Dermacentor spp. (D. variabilis, D. andersoni and D. albipictus) are known to be vectors of anaplasmosis [14]. While D. reticulatus is known to be a vector of Babesia canis [24], Rickettsia slovaca [25] and Coxiella burnetii $[26,27]$, the vector competency of this tick for $A$. marginale has not been determined until now.

The A. marginale strain used in this study originated from Zaria, Nigeria. Although bovine anaplasmosis occurs in large areas of Africa and a few isolates from South Africa 
(A)

\begin{tabular}{|c|c|}
\hline Repeat form & Encoded sequence \\
\hline A & DDSSSASGQQQESSVSSQSE-ASTSSQLG-- \\
\hline 54 & 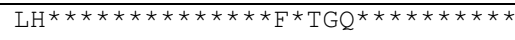 \\
\hline 55 & 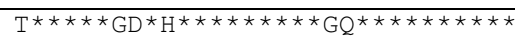 \\
\hline F & 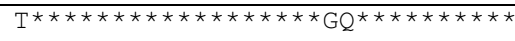 \\
\hline
\end{tabular}

(B)

\begin{tabular}{cccc|c|c}
$\begin{array}{c}\text { A. } \\
\begin{array}{c}\text { marginale } \\
\text { isolate }\end{array}\end{array}$ & Origin & Genbank accession No. & \multicolumn{2}{c}{ Structure of MSP1a tandem repeats } & $\begin{array}{c}\text { No. of } \\
\text { MSP1a } \\
\text { repeats }\end{array}$ \\
Zaria & Nigeria & EU106083 & 54 & 55 & F \\
\cline { 3 - 5 } 3
\end{tabular}

Figure 2

Sequence and structure of MSPIa tandem repeats in the Zaria isolate of A. marginale. (A) The one letter amino acid code was used to depict the different sequences found in MSPI a repeats. Asterisks indicate identical amino acids and gaps indicate deletions/insertions with respect to the reference repeat $A$. (B) The structure of the MSP la repeats region was represented using the repeat forms described in (A). Description of MSPIa repeats was updated after de la Fuente et al. [22].

have been characterized, this isolate from West Africa had not been reported previously and proved to have unique msp1a and msp4 sequences. The A. marginale msp4 gene, which is a stable marker for the genetic characterization of strains, does not undergo antigenic variation when cycling between tick and mammalian hosts [28]. MSP1a, encoded by $m s p 1 \alpha$, is involved in the adhesion and transmission of A. marginale by ticks and varies in the number and sequence of amino-terminal tandem repeats among geographic strains [22].

\section{Conclusion}

In this research we have demonstrated the vector competency of male $D$. reticulatus as an experimental biological vector of $A$. marginale by intrastadial transmission. Further studies are needed to confirm the vectorial role of $D$. reticulatus in Europe by use of $A$. marginale isolates derived from naturally infected cattle and ticks from endemic areas. Dermacentor spp. from A. marginale endemic regions should be studied, including $D$. marginatus which is commonly found on cattle and wildlife reservoir hosts.

\section{Methods}

\section{Experimental animals}

Two Holstein-Friesian calves, 8 months of age (No. 4291 and No. 9191), were used. Both animals had no previous exposure to ticks and were confirmed to be A. marginale free by examination of Giemsa-stained blood smears and $m s p 4$ PCR. All the ticks feeding and A. marginale infection were approved by the Animal Experiments Committee (DEC) of the Faculty of Veterinary Medicine, Utrecht Uni- versity (DEC No. 0604.0801). Both animals were euthanized at the end of the experiment.

\section{A. marginale isolate}

A Nigerian A. marginale isolate used for these studies was obtained from a naturally infected bovine from Zaria, Nigeria in 1986. This isolate was subsequently passaged in splenectomized calves, and blood samples were collected at the peak of parasitemia, prepared with $10 \%$ DMSO as stabilate and stored in $2 \mathrm{ml}$ aliquots in liquid nitrogen.

\section{Ticks}

Adult D. reticulatus ticks were collected during October 2006. by dragging vegetation in the area of the Dintelse Gorzen, The Netherlands. The absence of A. marginale infection in collected ticks was confirmed in 344 randomly selected ticks by use of an A. marginale specific PCR followed by reverse line blot hybridization (RLB) [21]. The ticks were maintained in the laboratory at $20^{\circ} \mathrm{C} / 90 \%$ relative humidity. Male ticks, allowed to acquire infection by feeding on an infected calf, were used for these studies because of their putative role in transmission of $A$. marginale $[15,16]$.

\section{Infection of ticks}

For infection of calves, the A. marginale blood stabilate was thawed and inoculated intravenously (IV) into the jugular vein of an eight-month old non-splenectomized and tick-naïve Holstein-Friesian calf (No. 4291). Rectal temperature was measured and registered daily and calf was observed for anemia and other signs consistent with 
anaplasmosis. Giemsa-stained blood smears were made and examined daily during the acute stage of the infection and twice weekly during the persistent stage of the infection. The packed cell volume (PCV) was determined using the microhematocrit technique. On day 34 p.i., 5 female and 80 male D. reticulatus ticks were placed in cotton patches glued to shaved area on the back of the calf. The ticks were allowed to acquisition feed for 7 days, after which the engorged females were removed and discarded and the fed male ticks were placed in an incubator at $20^{\circ} \mathrm{C}$ with $90 \%$ relative humidity and a $12: 12 \mathrm{~h}$ photoperiod for 7 days. This holding period provided time for the development and multiplication of $A$. marginale in tick midguts and other tissues [29]. Thirty male ticks were randomly selected and cut in half with a razor blade separating the right and left sides. The salivary gland from one tick half was dissected for PCR testing, while the other tick half was fixed for light microscopy studies.

\section{Transmission feeding}

A second eight-month old, tick-naïve and non-splenectomized Holstein-Friesian calf (No. 9191) was used for the transmission feeding of D. reticulatus. A group of 30 acquisition fed male D. reticulatus ticks was allowed to feed a second time for 7 days on this calf. After transmission feeding, ticks were removed and the salivary glands from one half of each tick were dissected for subsequent $m s p 4$ PCR testing. Body temperature was recorded daily and calf observed closely for the signs of illness. Blood samples were collected from the calf for determination the percent reduction PCV using the microhematocrit technique and for the preparation of Giemsa-stained blood smears. DNA was extracted from the blood samples and tested for the presence of A. marginale by the msp4 PCR [22].

\section{Light microscopy studies}

For light microscopy studies, a half of each tick was fixed in $2 \%$ glutaraldehyde in O.2 M sodium cacodylate buffer. The halves were then post fixed in osmium tetraoxide in O.2 M sodium cacodylate buffer, dehydrated in graded series of ethanol $(70 \%-100 \%)$ and embedded in epoxy resin. Thick sections $(1.0 \mu \mathrm{m})$ were cut and stained with Malory's stain for observation with a light microscope. Light micrographs were recorded with Leica DM LB with Spotcam camera system (Oklahoma State University, Stillwater, OK, USA).

\section{Molecular Diagnostics}

DNA was extracted from $200 \mu \mathrm{l}$ of blood and from individual tick salivary glands using NucleoSpin DNA extraction kit (Macherey-Nagel, Düren, Germany) following the manufacturer's protocol for the purification of genomic DNA from blood and insects. The DNA was eluted with water and stored at $-20^{\circ} \mathrm{C}$. A PCR assay amplifying the $A$. marginale msp4 gene was performed on blood samples of the two calves used for tick feeding and $D$. reticulatus salivary gland DNA samples, followed by sequencing as described previously [30].

The $m s p 1 \alpha$ gene was amplified from DNA extracted from the blood of $A$. marginale infected calves and tick salivary glands as described previously [22], but using forward primer MSP1aATG: 5'-TGTGTGTGTGTTATGT-3' instead of primer MSP1aP. Amplified and column purified samples were cloned in the pGEM-T vector (Promega) following the manufacturer's protocol and used directly for sequencing (Secugen SL, Madrid, Spain). The resulting $m s p 1 \alpha$ and $m s p 4$ gene sequences were compared to sequence data available from GenBank using the BLAST 2.2.15 program [31]. Multiple sequence alignment was performed using the program Align X (Vector NTI Suite V5.5., Invitrogen, North Bethesda, MD USA) with an engine based on the Clustal W algorithm [32].

\section{Authors' contributions}

$\mathrm{ZZ}$ carried out most of experiments and drafted the manuscript. AN contributed to the design of the study and acquisition of the data and helped with drafting the manuscript. JF contributed to acquisition of molecular biology data and helped with drafting and revision of the manuscript. KK performed the light microscopy study and helped with drafting and revision of the manuscript. FJ participated in design and coordination of the study and helped with drafting and revision of the manuscript. All authors read and approved the final manuscript.

\section{Acknowledgements}

This research was supported by grants from the European Community, INCO-DEV program (project No. 0037 I3), entitled 'Epidemiology and new generation vaccines for Ehrlichia and Anaplasma infections of ruminants', the Junta de Comunidades de Castilla-La Mancha, Spain (project 06036-00 ICSJCCM), entitled "Epidemiología de zoonosis transmitidas por garrapatas en Castilla - La Mancha" and was facilitated through the Integrated Consortium on Ticks and Tick-borne Diseases (ICTTD-3), financed by the International Cooperation Program of the European Union, coordination action project No. 51056I.

\section{References}

I. Dumler JS, Barbet AF, Bekker CP, Dasch GA, Palmer GH, Ray SC, Rikihisa $Y$, Rurangirwa FR: Reorganization of genera in the families Rickettsiaceae and Anaplasmataceae in the order Rickettsiales: unification of some species of Ehrlichia with Anaplasma, Cowdria with Ehrlichia and Ehrlichia with Neorickettsia, descriptions of six new species combinations and designation of Ehrlichia equi and 'HGE agent' as subjective synonyms of Ehrlichia phagocytophila. Int J Syst Evol Microbiol 200I, 5 I (Pt 6):2I 45-2I65.

2. Kuttler KL: Anaplasma infections in wild and domestic ruminants: a review. J Wild Dis 1984, 20(I): 12-20.

3. McGuire TC, Davis WC, Brassfield AL, McElwain TF, Palmer GH: Identification of Anaplasma marginale long-term carrier cattle by detection of serum antibody to isolated MSP-3. J Clin Microbiol I99I, 29(4):788-793.

4. Ceci L, Carelli G: Tick-borne diseases of livestock in Italy: general review and results of recent studies carried out in the Apulia region. Parassitologia 1999, 4 I Suppl I:25-29. 
5. de la Fuente J, Torina A, Caracappa S, Tumino G, Furla R, Almazan C, Kocan KM: Serologic and molecular characterization of Anaplasma species infection in farm animals and ticks from Sicily. Vet Parasitol 2005, I 33(4):357-362.

6. Caeiro V: General review of tick species present in Portugal. Parassitologia 1999, 4 I Suppl I: I I-I5.

7. de la Fuente J, Vicente J, Hofle U, Ruiz-Fons F, Fernandez De Mera IG, Van Den Bussche RA, Kocan KM, Gortazar C: Anaplasma infection in free-ranging Iberian red deer in the region of CastillaLa Mancha, Spain. Vet Microbiol 2004, I 00(3-4): I63-173.

8. Baumgartner W, Schlerka G, Fumicz M, Stoger J, Awad-Masalmeh M, Schuller W, Weber P: Seroprevalence survey for Anaplasma marginale-infection of Austrian cattle. Zentralbl Veterinarmed $B$ 1992, 39(2):97-104

9. Hofmann-Lehmann R, Meli ML, Dreher UM, Gonczi E, Deplazes P, Braun U, Engels M, Schupbach J, Jorger K, Thoma R, Griot C, Stark KD, Willi B, Schmidt J, Kocan KM, Lutz H: Concurrent infections with vector-borne pathogens associated with fatal hemolytic anemia in a cattle herd in Switzerland. J Clin Microbiol 2004, 42(8):3775-3780.

10. Hornok S, Elek V, de la Fuente J, Naranjo V, Farkas R, Majoros G, Foldvari G: First serological and molecular evidence on the endemicity of Anaplasma ovis and A. marginale in Hungary. Vet Microbiol 2007, I 22(3-4):316-322

II. Ewing SA: Transmission of Anaplasma marginale by arthropods. Mississippi State University, MS, USA; 1981:395-423.

12. Kocan KM, de la Fuente J, Blouin EF, Garcia-Garcia JC: Anaplasma marginale (Rickettsiales: Anaplasmataceae): recent advances in defining host-pathogen adaptations of a tickborne rickettsia. Parasitology 2004, I 29 Suppl:S285-300.

13. Scoles GA, Ueti MW, Noh SM, Knowles DP, Palmer GH: Conservation of transmission phenotype of Anaplasma marginale (Rickettsiales: Anaplasmataceae) strains among Dermacentor and Rhipicephalus ticks (Acari: Ixodidae). J Med Entomol 2007, 44(3):484-49।.

14. Stiller D, Kocan KM, Edwards W, Ewing SA, Barron JA: Detection of colonies of Anaplasma marginale in salivary glands of three Dermacentor spp infected as nymphs or adults. Am J Vet Res 1989, 50(8): $138 \mid-1385$

15. Kocan KM, Goff WL, Stiller D, Claypool PL, Edwards W, Ewing SA Hair JA, Barron SJ: Persistence of Anaplasma marginale (Rickettsiales: Anaplasmataceae) in male Dermacentor andersoni (Acari: Ixodidae) transferred successively from infected to susceptible calves. J Med Entomol 1992, 29(4):657-668.

16. Kocan KM, Stiller D, Goff WL, Claypool PL, Edwards W, Ewing SA McGuire TC, Hair JA, Barron SJ: Development of Anaplasma marginale in male Dermacentor andersoni transferred from parasitemic to susceptible cattle. Am J Vet Res 1992, 53(4):499-507.

17. Dreher UM, Hofmann-Lehmann R, Meli ML, Regula G, Cagienard AY, Stark KD, Doherr MG, Filli F, Hassig M, Braun U, Kocan KM, Lutz H Seroprevalence of anaplasmosis among cattle in Switzerland in 1998 and 2003: no evidence of an emerging disease. Vet Microbiol 2005, 107(I-2):7I-79.

18. Estrada-Pena A, Bouattour A, Camicas JL, Walker AR: Ticks of domestic animals in the mediterranean region: a guide to identification of species. Zaragoza , University of Zaragoza; 2004:|31.

19. Dautel H, Dippel C, Oehme R, Hartelt K, Schettler E: Evidence for an increased geographical distribution of Dermacentor reticulatus in Germany and detection of Rickettsia sp. RpA4. Int J Med Microbiol 2006, 296 Suppl 40: I49-I56.

20. Sreter T, Szell Z, Varga I: Spatial distribution of Dermacentor reticulatus and Ixodes ricinus in Hungary: evidence for change? Vet Parasitol 2005, I 28(3-4):347-35 I.

21. Nijhof AM, Bodaan C, Postigo M, Nieuwenhuijs H, Opsteegh M, Franssen L, Jebbink F, Jongejan F: Ticks and Associated Pathogens Collected from Domestic Animals in the Netherlands. Vector Borne Zoonotic Dis 2007 in press. [Epub ahead of print]

22. de la Fuente J, Ruybal P, Mtshali MS, Naranjo V, Shuqing L, Mangold AJ, Rodriguez SD, Jimenez R, Vicente J, Moretta R, Torina A, Almazan C, Mbati PM, de Echaide ST, Farber M, Rosario-Cruz R, Gortazar C, Kocan KM: Analysis of world strains of Anaplasma marginale using major surface protein I a repeat sequences. Vet Microbiol 2007, I I 9(2-4):382-390.
23. Poncet $A$, Chossonery $A$, Brugère-Picoux J: L'anaplasmose bovine. Bull Soc Vét Prat de France 1987, 7 I (7):38I-400.

24. Uilenberg G, Franssen FF, Perie NM, Spanjer AA: Three groups of Babesia canis distinguished and a proposal for nomenclature. Vet $Q$ 1989, I I (I):33-40.

25. Raoult D, Lakos A, Fenollar F, Beytout J, Brouqui P, Fournier PE: Spotless rickettsiosis caused by Rickettsia slovaca and associated with Dermacentor ticks. Clin Infect Dis 2002, 34(10): $|33|-1336$

26. Jongejan F: Integrated control of ticks and tick-borne diseases. Parassitologia 1999, 4I Suppl 1:57-58.

27. Estrada-Pena $A$, Jongejan F: Ticks feeding on humans: a review of records on human-biting Ixodoidea with special reference to pathogen transmission. Exp Appl Acarol 1999, 23(9):685-7I5.

28. de la Fuente J, Lew A, Lutz H, Meli ML, Hofmann-Lehmann R, Shkap V, Molad T, Mangold AJ, Almazan C, Naranjo V, Gortazar C, Torina A, Caracappa S, Garcia-Perez AL, Barral M, Oporto B, Ceci L, Carelli G, Blouin EF, Kocan KM: Genetic diversity of anaplasma species major surface proteins and implications for anaplasmosis serodiagnosis and vaccine development. Anim Health Res Rev 2005, 6(I):75-89.

29. Kocan KM, Goff WL, Stiller D, Edwards W, Ewing SA, Claypool PL, McGuire TC, Hair JA, Barron S): Development of Anaplasma marginale in salivary glands of male Dermacentor andersoni. Am J Vet Res 1993, 54(1): I07-II 2.

30. de la Fuente J, Atkinson MW, Naranjo V, de Mera IGF, Mangold AJ Keating KA, Kocan KM: Sequence analysis of the msp4 gene of Anaplasma ovis strains. Veterinary Microbiology 2007, II9(24):375-38I.

3I. NCBI BLAST [http://www.ncbi.nlm.nih.gov/BLAST/]

32. Thompson JD, Higgins DG, Gibson TJ: CLUSTAL W: improving the sensitivity of progressive multiple sequence alignment through sequence weighting, position-specific gap penalties and weight matrix choice. Nucleic Acids Res 1994 22(22):4673-4680.

Publish with BioMed Central and every scientist can read your work free of charge

"BioMed Central will be the most significant development for disseminating the results of biomedical research in our lifetime. "

Sir Paul Nurse, Cancer Research UK

Your research papers will be:

- available free of charge to the entire biomedical community

- peer reviewed and published immediately upon acceptance

- cited in PubMed and archived on PubMed Central

- yours - you keep the copyright
BioMedcentral 